\title{
Imperialismo contra ultraimperialismo: conexões teóricas e evidência empírica para o período de 1990 a 2010
}

Leonardo de Magalhães Leite*

Resumo: A polêmica entre imperialismo e ultraimperialismo marcou o debate marxista no começo do século XX, sendo polarizada por Lênin e Kautski. Aparentemente, os acontecimentos do capitalismo contemporâneo demonstrariam que a tese ultraimperialista seria a vencedora, já que as rivalidades entre as principais potências não seriam observadas no campo militar. Argumenta-se que esse aparente ultraimperialismo seria uma fase particular dentro do imperialismo, cuja manifestação foi possível devido à existência de um líder indiscutível. Resultados empíricos contribuem com essa hipótese.

Palavras-chave: Economia marxista. Capitalismo contemporâneo. Imperialismo.

\section{Imperialism against ultra-imperialism: theoretical connections and empirical evidence for the period 1990-2010}

\begin{abstract}
The controversy between imperialism and ultra-imperialism marked the Marxist debate in the early twentieth century, being polarized by Lenin and Kautsky. Apparently, the events of contemporary capitalism demonstrate that the thesis of ultra-imperialism would be the winner, as the rivalry between the major powers would not be observed in the military field. It is argued that this apparent ultra-imperialism would be a particular phase of imperialism, whose manifestation was possible due to the existence of an undisputed leader. Empirical results contribute to this hypothesis.
\end{abstract}

Keywords: Marxist economics. Contemporary capitalism. Imperialism.

Classificação JEL: B51, F54, F60.

\section{Introdução}

A dimensão da crise atual enseja argumentos de que se trata de uma crise estrutural e, com isso, representaria o momento de transição entre fases do capitalismo. Considera-se que a atual fase de seu desenvolvimento histórico, marcada pelo endividamento como contraponto à pequena capacidade de crescimento (Cipolla, 2010), atingiu virtualmente seu limite. Tanto a crise do subprime quanto a da dívida soberana em países europeus são faces do mesmo fenômeno: o enorme endividamento realizado nos últimos 30 anos seja na esfera pública ou na privada ${ }^{1}$.

Além da necessária reestruturação do processo de crescimento econômico nas economias centrais, pode estar em curso uma diminuição relativa entre a distância do principal polo hegemônico vis-à-vis os demais integrantes do sistema mundial. Esses fatores se coadunam e

\footnotetext{
* Professor Assistente, Departamento de Ciências Econômicas de Campos, Universidade Federal Fluminense. E-mail: leonardoleite.uff@gmail.com

${ }^{1}$ Nas principais economias avançadas, as dívidas do setor público e do setor privado representam mais de $300 \%$ do PIB destes países. Em casos como Japão ou Reino Unido, a dívida é mais do que quatro vezes o tamanho do PIB (ROXBURGH et al., 2010).
} 
constituem os elementos indicativos de uma transição na economia mundial. Seguindo a tipologia das etapas do desenvolvimento capitalista, proposta por Sakellaropoulos (2009), baseado em Lenin (2008), o período que se estende do final da década de 1970 aos dias atuais se configura como a terceira fase dentro do último estágio de desenvolvimento do capitalismo: o imperialismo.

Como uma tentativa de contribuir para os debates atuais acerca da natureza do pós-crise, ou da nova forma em que o capitalismo se reorganizará, este trabalho resgata um debate central na transição do capitalismo da livre concorrência para o capitalismo monopolista: imperialismo contra ultraimperialismo. Por um lado, a tese defendida por Lenin, Bukharin e Rosa Luxemburgo era de que o estágio monopolista do capitalismo, ou o imperialismo, constituía-se como a última etapa de seu desenvolvimento. Por outro lado, a tese do ultraimperialismo, defendida por Kautski, argumentava que o imperialismo seria sucedido por uma espécie de confederação das principais potências econômicas, configurando uma nova fase pacífica de desenvolvimento do capitalismo.

A hipótese que esse trabalho assume é que o estágio do imperialismo, tal qual descrito por Lenin (2008), abarca fases distintas. Inclusive, uma fase similar ao ultraimperialismo kautskiano que está sendo chamado aqui de aparente ultraimperialismo - pode manifestar-se dentro do imperialismo. Embora esses dois conceitos abarquem, em si, teses divergentes, este artigo pretende demonstrar como ambos podem se relacionar por meio de uma adaptação no modelo teórico do imperialismo. O se faz é introduzir uma mediação utilizando-se o argumento de líder indiscutível, apresentado por Baran e Sweezy (1966). Com isso, o aparente ultraimperialismo que se manifesta na economia mundial pós-1945 não se constitui como um estágio superior ao imperialismo, mas, sim, como uma fase dentro dele, possível graças à existência do líder indiscutível - um Estado que, pelo seu poderio militar e amplo leque de alianças, assume o topo da cadeia interimperialista global e atua de forma indiscutível.

Portanto, o objetivo central deste artigo é contribuir para o entendimento da etapa atual do capitalismo. Especificamente, pretende-se: (i) retomar o debate teórico entre imperialismo e ultraimperialismo; (ii) ajustar o modelo teórico do imperialismo para os acontecimentos do capitalismo contemporâneo; e (iii) identificar empiricamente a existência do líder indiscutível, bem como examinar a evolução recente da distância desse líder para os demais grupos da economia mundial. A análise empírica foi realizada por meio da técnica estatística conhecida como análise de agrupamentos (clusters).

O texto se subdivide em mais cinco seções além desta introdução. Na segunda, são analisados os fundamentos da teoria do imperialismo e como ele reflete a tendência expansionista do capital. Na terceira é resgatada a polêmica entre imperialismo e ultraimperialismo, demonstrando o grau de antagonismo entre ambos. Na quarta, é realizada uma tentativa de síntese desse debate por 
meio da adaptação do modelo teórico do imperialismo ao conceito do líder indiscutível. A quinta seção discute como essa síntese pode ser ajustada aos acontecimentos do capitalismo contemporâneo, ao mesmo tempo em que o modelo empírico é executado. Por fim, são tecidas algumas considerações finais.

\section{A natureza expansionista do capital e o imperialismo}

A transição entre os séculos XIX e XX representa um ponto de inflexão na trajetória do desenvolvimento do capitalismo. Inaugurava-se a era do capital financeiro, com as grandes corporações se consolidando em grandes oligopólios e substituindo a livre-concorrência como a esfera principal de acumulação do capital (HILFERDING, 1985). A luta econômica pelos mercados consumidores e de matérias-primas opunha grupos empresariais e, no limite, os Estados nacionais. O imperialismo, como codinome para o novo capitalismo que surgia, refletia não as disputas interestatais por si mesmas, mas, principalmente, a nova forma de acumulação de capital.

No início do século XX, quando o novo capitalismo substituiu o velho, "o imperialismo expressava uma efetiva revolução capitalista no capitalismo; as transformações sociais que induzia não eram fictícias, mas reais" (FONTES, 2007, p. 56).

Hilferding (1985) foi o primeiro autor marxista a interpretar essas reais transformações sociais pelas quais o capitalismo passava. Entretanto, as contradições concretas com as quais o capitalismo se defrontava estavam, de certa forma, submersas. Lenin (2008), em 1916, documentando com evidências factuais conseguiu trazer à superfície, "evidenciar as contradições" (FONTES, 2007, p. 55) da fase em que o capitalismo ingressara.

Nessa perspectiva, Lenin (2008, p. 23) mostra que os monopólios e cartéis "passam a ser uma das bases de toda a vida econômica", tanto na esfera financeira quanto na industrial. Nos setores mais intensivos em tecnologia, a partilha do mundo entre os capitalistas começa a ser vista.

Ao relacionar a partilha entre as associações de capitalistas e a partilha entre os Estados, Lenin (2008) afirmou que

[...] a época do capitalismo contemporâneo mostra-nos que se estão estabelecendo determinadas relações entre os grupos capitalistas com base na partilha econômica do mundo, e que, ao mesmo tempo, em ligação com isto, se estão estabelecendo entre os grupos políticos, entre os Estados, determinadas relações com base na partilha territorial do mundo, na luta pelas colônias, na luta pelo território econômico. (LENIN, 2008, p. 75).

Rosa Luxemburg (1976, p. 392) afiançou que “o imperialismo é a expressão política do processo de acumulação do capital, em sua luta para conquistar a regiões não capitalistas que não se encontrem ainda dominadas". Para a autora, essa luta é enfrentada para "encontrar mercados para seu excesso de produção, e possibilidades de capitalização para sua mais-valia". A contradição do 
imperialismo, então, é o fato de que quanto mais rapidamente ele anexe territórios não capitalistas, mais rapidamente caminha para sua destruição. Isto é, “o imperialismo é tanto um método histórico para prolongar a existência do capital, como um meio seguro para objetivamente pôr um fim a sua existência” (LUXEMBURG, 1976, p. 392). Como isso, segundo Luxemburg (1976, p. 392), põe por fim “a esperança de um desenvolvimento pacífico da acumulação do capital” a autora ilumina a questão que seus sucessores teóricos irão discutir.

Para Luxemburg (1976), a acumulação capitalista tem dois aspectos distintos. Por um lado, a acumulação ocorre onde se produz a mais-valia. Existe, entretanto, um segundo lado da acumulação do capital, que é aquele que se realiza entre o capital e as formas de produção não capitalista: "Esse processo desenvolve-se no cenário mundial. Aqui, os métodos são a política colonial, o sistema de empréstimos internacionais, a política de interesses privados, a guerra” (LUXEMBURG, 1976, p. 398). Nesse tópico, a autora evoca a importância do poder político, que se trata apenas do "veículo do processo econômico". Na realidade, afirma Luxemburg (1976, p. 398): "Os dois aspectos da acumulação do capital acham-se ligados organicamente pelas condições de reprodução do capital, e só a reunião de tais aspectos permite o curso histórico do capital” Esse movimento histórico, entretanto, "prepara, em meio a convulsões cada vez mais violentas, sua própria ruína" (LUXEMBURG, 1976, p. 398). É importante observar que Luxemburg (1976) assumiu os mesmos prognósticos que, mais tarde, Bukharin (1988) e Lenin (2008), diferentemente de Kautski (1914), assumiram.

De fato, as conclusões que Kautski assumiu a partir de sua interpretação do imperialismo, decorreram da questão da desproporcionalidade dos ramos de produção. Para ele, o imperialismo decorreu da tendência das regiões industriais em anexar ou submeter as regiões agrárias ao seu domínio.

Para Kautski (2002a), a desproporcionalidade decorre do fato de o processo de acumulação de capital ser mais rápido na indústria do que na agricultura. Além de ser provocado por fatores de ordem técnica e social, Kautski $\left(2002^{\mathrm{a}}\right.$, p. 453) apontou que "na indústria capitalista, incide um poderoso fator que, na agricultura, mesmo para a empresa capitalista, tem escassa importância: $a$ concorrência, a luta recíproca entre as diversas empresas para colocar seus produtos". Portanto, o argumento central de Kautski (2002a) para essa questão é o de que a produção industrial aumenta desproporcionalmente à produção agrícola. Segue-se uma oferta de mercadorias industrializadas superior à demanda. $\mathrm{O}$ excesso não encontrará mercado e o preço cairá, precedendo uma crise (KAUTSKI, 2002a).

Para não se chegar a esse ponto, Kautski (2002a, p. 455) expõe: “a acumulação capitalista na indústria só pode avançar e desenvolver-se livremente se ampliar constantemente a área agrícola 
que lhe abastece e para a qual destina os seus produtos". A tendência crescente da desproporcionalidade entre os setores "transforma-se em estímulo cada vez mais intenso [...] a ampliar o território agrícola" (KAUTSKI, 2002a p. 455-456), que fornece víveres e insumos e constitui mercado consumidor. O autor identifica que a "forma particular dessa tendência é o imperialismo" (KAUTSKI, 2002a, p. 455). O autor, portanto, assumiu o imperialismo "como um tipo particular de política capitalista" (KAUTSKI, 2002b, p. 471).

A necessidade de territórios agrícolas, para Kautski (2002a), assume um formato semelhante, pouco mais genérico, que o da necessidade por territórios para exportar capitais de Hilferding (1985). Para o autor, quando diversos países lutam por territórios econômicos, a concorrência acirra-se. A disputa econômica por mercados fornecedores de insumos e escoadouros da produção "torna-se rapidamente uma luta pelo poder, a ser conduzida com armas políticas" (HILFERDING, 1985, p. 304). Com a “anexação de territórios estrangeiros pela política colonial” (HILFERDING, 1985p. 305), a feroz concorrência desaparece. Partes do mercado mundial foram incorporadas a alguns mercados nacionais, sendo que "[...] aqui entrechocam-se diretamente, de forma hostil, os interesses de países" (HILFERDING, 1985, p. 305).

Um dos objetivos da política do capital financeiro, para Hilferding (1985, p. 306), é converter o "território econômico em área de exploração para as associações monopolistas nacionais". Esse autor apontou diferenças, em termos do imperialismo, entre as duas regiões mais avançadas do ponto de vista da acumulação do capital, os Estados Unidos e a Europa. Segundo o autor, os Estados Unidos "são em si um grande território econômico, suficiente também para a era do imperialismo, cuja expansão é, de resto, orientada geograficamente. O movimento panamericano [...] está apenas no começo" (HILFERDING, 1985, p. 308). Já na Europa, “a fragmentação estatal criou interesses econômicos antagônicos", onde as partes são "mais ou menos similares e, por isso, em concorrência hostil e com posição antagônica" (HILFERDING, 1985p. 308).

Para Hilferding (1985, p. 308), tal antagonismo "aumenta extraordinariamente pela ação da política econômica do capital financeiro", já que o capital busca, em comum, "territórios virgens, cuja colonização pode ser de grande importância precisamente para os grupos capitalistas mais poderosos" (HILFERDING, 1985, p. 308). Do antagonismo interestatal europeu derivaram-se relações de dependência entre alguns países; porque se institui implicitamente uma hierarquia de poder econômico.

Portanto, o Estado-nação, em Hilferding (1985), apesar de sua subordinação ao capital financeiro, é de vital importância às pretensões da classe dirigente nacional. A luta pelo domínio do mercado mundial "será tanto mais exacerbada quanto mais desenvolvido for o capital financeiro e 
mais forte for seu empenho pela monopolização de porções do mercado mundial para o capital nacional" (HILFERDING, 1985, p. 311). Esse teórico fez um auspicioso alerta em relação à Alemanha: "A contradição entre o desenvolvimento do capitalismo alemão e a insignificância relativa de seu território econômico aumentou [...] extraordinariamente" (HILFERDING, 1985, p. 311). O país não possui possessões coloniais. "Trata-se de uma situação que necessariamente agrava de forma extraordinária o confronto entre Alemanha e Inglaterra com seus satélites, uma situação que impele a uma solução violenta” (HILFERDING, 1985, p. 311).

Aliás, Hilferding (1985, p. 312) alertou que "a própria exportação de capital cria tendências que resistem à semelhante ação violenta", já que "a disparidade do desenvolvimento industrial acarreta certa diferenciação nas formas de exportação de capital” (HILFERDING, 1985, p. 312). Países com desenvolvimento industrial mais avançado nos aspectos da técnica e da organização tendem a participar da exportação de capital industrial de forma mais intensa. É o caso de Alemanha e dos EUA. Já "países com desenvolvimento capitalista antigo participam da exportação de capital mais em forma de capital de empréstimo do que em forma de implantação de fábricas" (HILFERDING, 1985, p. 312). Assim, surgem "tendências à solidariedade dos interesses capitalistas internacionais" (HILFERDING, 1985, p. 312). Por exemplo, “o capital francês estará interessado como capital de empréstimo nos progressos das indústrias alemãs na América do Sul" (HILFERDING, 1985, p. 312). Assim, Hilferding (1985) levantou os argumentos tanto dos teóricos que prognosticavam conflitos bélicos por causa do imperialismo, quanto dos teóricos que argumentavam que o imperialismo criaria sua própria saída pacífica.

Para Hilferding (1985, p. 315), a ideologia do imperialismo surgirá como oposto "dos velhos ideais liberais", já que o tipo de atuação estatal que o capital financeiro necessitava era o oposto da ideologia liberal. Em importante referência, na qual trata do tipo de Estado que o capital financeiro precisa, Hilferding (1985, p. 314) afirmou que ele necessita de um "Estado que possa intervir em toda parte do mundo para converter o mundo inteiro em área de investimento para seu capital financeiro". Novamente enfatizou a importância de um Estado forte, que intervenha em complementaridade às necessidades do capital financeiro.

Bukharin (1988) é outro autor que aponta a necessidade do Estado para o capital financeiro. O autor apresentou os vários métodos de ação empregados pelo imperialismo, que vão desde rebaixamento forçado de preços, dumping, restrição de crédito etc., até se atingir o militarismo. Afirmou que: "antes de tudo, a luta entre os trustes capitalistas nacionais decide-se pelo confronto de suas respectivas forças militares, já que a potência militar do país constitui a última instância a que fazem apelo os grupos capitalistas nacionais" (BUKHARIN, 1988, p. 118) Ele mostrou que, de fato, assistia-se a uma corrida armamentista entre os países mais avançados. Por esse motivo, 
afirmou que "o domínio do capital financeiro pressupõe o imperialismo e o militarismo. Nesse sentido, o militarismo é um fenômeno histórico tão típico quanto o capital financeiro" (BUKHARIN, 1988, p. 120, grifo nosso).

Luxemburg (1976), em sua tentativa de desvendar o enigma da reprodução ampliada do capital, afirmou que o militarismo é mais um campo para a acumulação do capital. Assim, além de seu papel tradicional de responsável pela defesa bélica, ele assume um segundo papel. Ao extrair parte da renda social no formato de tributos, o Estado pode criar um mercado novo, isto é, novas possibilidades de realização da mais-valia, se demandar "produtos como engenhos de guerra do militarismo, os armamentos navais e de terra" (LUXEMBURG, 1976, p. 403). Do ponto de vista do capital individual, "ganha um pequeno grupo de grandes industriais através do ramo de armamentos" (LUXEMBURG, 1976, p. 404).

O militarismo, então, “desempenha estas duas funções: assegura [...] tanto a manutenção do órgão de dominação capitalista - o exército permanente - como a criação de um magnífico campo de acumulação para o capital" (LUXEMBURG, 1976, p. 409). Dessa forma, o militarismo que acompanha "a concorrência mundial intensificada para a conquista de condições de acumulação transforma-se assim, para o próprio capital, num magnífico campo de acumulação" (LUXEMBURG, 1976, p. 411).

Concomitante ao processo de acirramento das condições da concorrência mundial, Lenin (2008) afirmou que as grandes potências passam a partilhar o mundo entre si. O "enorme ascenso das conquistas coloniais" (LENIN, 2008, p. 78) começa exatamente na transição entre o estágio da livre-concorrência e o estágio imperialista. De tal modo, a partilha territorial mais intensa (final do século XIX e começo do século XX) coincide com esse novo estágio hegemonizado por cartéis, trustes e sindicatos internacionais, sob a coordenação do capital financeiro (LENIN, 2008).

$\mathrm{Na}$ relação do capital financeiro com os Estados nacionais, Lenin (2008) afirmou: “o capital financeiro é uma força tão considerável, pode dizer-se tão decisiva, em todas as relações econômicas e internacionais, que é capaz de subordinar, e subordina realmente, mesmo os Estados que gozam da independência política mais completa" (LENIN, 2008, p. 82).

Para Lenin (2008, p. 83), “a particularidade fundamental do capitalismo moderno consiste na dominação exercida pelas associações monopolistas dos grandes patrões." Esse autor partiu das transformações da base econômica do capitalismo para chegar ao imperialismo como necessidade desse modo de produção. Nesse novo estágio, o capital precisa de novos territórios (econômicos e geográficos) para se expandir e manter o processo de acumulação (LENIN, 2008). Assim, continua Lenin (2008, p. 90), “[...] interpretado no sentido referido, o imperialismo representa em si, indubitavelmente, uma fase particular de desenvolvimento do capitalismo." 
Tal definição do imperialismo como sendo uma "fase", ou uma categoria determinada historicamente, é amplamente criticada por Kautski (2002b), que rejeita a necessária identificação entre "imperialismo e capitalismo moderno" (KAUTSKI, 2002b, p. 469). O mesmo autor parte para uma definição genealógica do termo imperialismo. Hoje, afirma Kautski (2002b), o significado a que se deve reportar o termo imperialismo é o mesmo que foi utilizado "pela primeira vez durante o império de Napoleão, para indicar sua política” (KAUTSKI, 2002b p. 470). Na Inglaterra no final do século XIX, "o termo indicava mais uma vez um tipo particular de política imperial" (KAUTSKI, 2002b, p. 470), que buscava estreitar as ligações britânicas com as colônias. Não foi ela que iniciou esse tipo de política, "mas foi ela que lhe forneceu o nome" (KAUTSKI, 2002b p. 470).

Referenciando-se em Hilferding, Kautski (2002b) reconhece que "o novo tipo de política imperial ou política mundial era uma consequência do desenvolvimento do capital industrial, da crescente importância da alta finança, das exportações de capitais” (KAUTSKI, 2002b, p. 470). Para Kautski (2002b), Hilferding utiliza o termo imperialismo para designar "um particular tipo de política, não uma 'fase econômica'. O imperialismo, de acordo com ele, é a política favorita do capital financeiro" (KAUTSKI, 2002b, p. 470-471). Prossegue afirmando que a melhor definição para o imperialismo é exatamente "um particular sistema de política" (KAUTSKI, 2002b, p. 471) e não uma fase. Portanto, o capital financeiro, a fase particular do capitalismo, é entendido como causa e o imperialismo, o tipo de política do capital financeiro é entendido como efeito (KAUTSKI, 2002b).

De fato, como analisa Brewer (1990), Hilferding não formulou uma teoria do imperialismo e por isso, em geral, não utiliza o termo "imperialismo". Opostamente, utilizou bastante termos como política protecionista moderna, política colonial moderna e política externa do capital financeiro. Quando Hilferding se referia ao imperialismo, sempre o citava como um conceito genérico para o militarismo e as tendências expansionistas do capitalismo (BREWER, 1990). Aliás, isso não é nenhum demérito dele. Diz Brewer (1990): “A razão por que Hilferding não construiu um conceito de imperialismo é clara; seu interesse era no desenvolvimento interno dos principais centros capitalistas, no surgimento do capital financeiro. Esse é o título do livro, é seu conceito, e ninguém pode tomar isso dele.” (BREWER, 1990, p. 107, tradução nossa).

Dessa forma, embora Kautski tenha embasado sua definição de imperialismo amplamente na obra de Hilferding, torna-se um pouco frágil, à medida que o próprio Hilferding não formulou uma teoria específica a respeito do assunto.

De fato, o próprio Bukharin (1988) apresenta uma perspectiva dúbia em relação à definição do imperialismo. Em alguns trechos de A Economia Mundial e o Imperialismo, nota-se que se 
refere ao imperialismo como política e, em outros, como uma fase determinada do desenvolvimento capitalista. A seguinte citação ilustra bem esse ponto: "Assim como o capitalismo [...] constitui uma época historicamente limitada, característica apenas dos últimos decênios, também o imperialismo, política do capitalismo financeiro, representa uma categoria especificamente histórica" (BUKHARIN, 1988, p. 107). Fácil a percepção de que Bukharin (1988) considerou o imperialismo com as duas perspectivas.

Lenin (2008) é o autor que mais enfatizou o imperialismo como uma fase, um estágio do desenvolvimento capitalista. Aliás, além de ser uma fase particular, trata-se da última fase do modo de produção capitalista.

\section{O debate entre imperialismo e ultraimperialismo}

Entretanto, o grande debate que agitou os círculos marxistas do começo do século $\mathrm{XX}$ foi em relação ao futuro do capitalismo, ou, melhor dizendo, ao imperialismo, ou o estágio do capitalismo monopolista, do capital financeiro. Decerto, o militarismo e a corrida armamentista, pré-Primeira Guerra Mundial, eram fenômenos vistos a olho nu. A questão era se o imperialismo faria com que os países mais avançados se digladiassem até a supressão do capitalismo ou se, ao invés da luta competitiva, eles se envolveriam em acordos mútuos de cooperação na exploração. Em outra perspectiva, a questão era se o capitalismo, na fase do imperialismo, atingira seu ponto máximo de desenvolvimento e contradição entre forças produtivas e relações de produção, ou se ainda possuiria margem de manobra à sua trajetória de desenvolvimento.

Sendo o imperialismo a política do capital financeiro, Kautski (2002a) questionou: "representa o imperialismo a última forma fenomênica possível da política mundial capitalista, ou ainda é possível outra?” (KAUTSKI, 2002a, p. 459). Referindo-se ao militarismo, Kautski (2002a) afirmou que a rivalidade crescente entre os países capitalistas industriais resulta na corrida armamentista, "fazendo com que a guerra mundial, há tanto tempo preconizada, seja enfim uma realidade" (KAUTSKI, 2002a, p. 460).

O problema, segundo Kautski (2002a), é que um conflito bélico representa uma ameaça para a economia capitalista. À exceção dos setores envolvidos na produção de armamentos, a corrida armamentista prejudica o processo de acumulação e de exportação de capitais, dado o amplo custo e esforço necessário para sustentá-la. Além disso, a guerra pode, também, agravar a pressão sobre o mercado de capitais, pois as taxas de juros são forçadas a aumentar, deteriorando ainda mais a economia capitalista no pós-guerra (KAUTSKI, 1914; 2002a). Assim, ao gerar a guerra, "o imperialismo cava seu próprio túmulo e, de instrumento de desenvolvimento do capitalismo, tornase um obstáculo" (KAUTSKI, 2002a, p. 461). Portanto, “todos os capitalistas com visão de longo 
prazo devem hoje gritar a seus companheiros: capitalistas de todo o mundo, uni-vos!” (KAUTSKI, 2002a, p. 460).

Kautski não considerou o imperialismo como o último mecanismo de desenvolvimento do capitalismo, portanto, uma mudança de rumo na direção capitalista; uma nova estratégia de acumulação se torna "possível, à medida que o imperialismo [...] representa apenas um meio, entre muitos, para favorecer a expansão do capitalismo" (KAUTSKI, 2002a, p. 462).

$\mathrm{Na}$ construção de seu argumento, ele se referenciou em Marx: "Pode-se dizer do imperialismo o que Marx disse do capitalismo: o monopólio gera a concorrência e a concorrência gera o monopólio" (KAUTSKI, 2002a, p. 462). E, continuando, chega ao clímax de seu raciocínio: "E assim, agora mesmo, da guerra mundial entre as grandes potências imperialistas, pode surgir um acordo entre os mais fortes, que ponha fim à corrida armamentista" (KAUTSKI, 2002a, p. 462 grifo nosso).

Assim, prossegue Kautski (2002a, p.462), "do ponto de vista puramente econômico", o capitalismo pode viver "uma nova fase, uma fase na qual a política dos cartéis se transfira para a política externa, uma fase de ultraimperialismo, que, naturalmente, devemos combater." E finaliza reforçando sua ideia: "do ponto de vista puramente econômico, [...] nada impede que essa violenta explosão termine por transformar o imperialismo em uma santa aliança entre os imperialistas" (KAUTSKI, 2002a, p. 463).

Em artigo posterior, Dois Artigos para uma Revisão, doravante Kautski (2002b), no qual seu objetivo é polemizar com Lensch e Cunow, dois autores marxistas da época, sobre o conceito do imperialismo, Kautski trouxe novas contribuições sobre o ultraimperialismo.

Os elementos materiais que o fizeram lançar a hipótese do ultraimperialismo são precisamente descritos na seguinte citação que, embora longa, é valiosa:

A derrota do movimento protecionista na Inglaterra, a redução das tarifas na América, a tendência ao desarmamento, a rápida redução das exportações de capital da França e da Alemanha nos últimos vinte anos antes da guerra, enfim, o crescente entrelaçamento entre os vários grupos do capital financeiro induziram-me a refletir sobre a possibilidade de que a atual política imperialista seja suplantada por uma nova política, ultraimperialista, que substitua a luta entre os capitais financeiros nacionais pela exploração comum do mundo, por parte do capital financeiro internacional unificado. Em todo caso, essa nova fase do capitalismo é imaginável. Que seja realizável, faltam ainda premissas suficientes para dizê-lo com segurança (KAUTSKI, 2002b, p. 488).

Claramente, a possibilidade do ultraimperialismo foi colocada por Kautski, mas foi cauteloso ao afirmar que se tratava de uma tendência inevitável, pois ainda não visualizava todas as condições materiais necessárias para isso. Novamente desconsiderou o imperialismo como o último estágio de desenvolvimento do capitalismo, ao afirmar que o considerou "como um fenômeno 
mutável e avaliado a possibilidade de sua superação por uma modalidade diferente de política do próprio capital financeiro" (KAUTSKI, 2002b, p. 489).

Embora Kautski (2002b) considerasse o ultraimperialismo possível, foi prudente ao afirmar tal possibilidade. O autor afirmou que, dependendo da saída da guerra, a situação poderia caminhar para dois lados distintos: por um lado, “[...] ela pode destruir completamente os frágeis germes do ultraimperialismo, exasperando o ódio nacional também entre os capitalistas das finanças, acelerando a corrida armamentista, tornando inevitável uma segunda guerra mundial" (KAUTSKI, 2002b, p. 489). Por outro lado, poder-se-ia chegar “[...] a um entendimento entre as nações, ao desarmamento, a uma paz duradoura, podem desaparecer as causas mais graves que, antes da guerra, levavam crescentemente ao colapso moral do capitalismo" (KAUTSKI, 2002b, p. 490). Assim, “[...] o ultraimperialismo poderá inaugurar uma nova era de esperança e expectativas no interior do capitalismo" (KAUTSKI, 2002b, p. 490).

Logo, o ultraimperialismo, para Kautski, seria a aliança entre os mais poderosos Estados industriais - na figura de uma possível federação desses Estados, que eliminariam a corrida armamentista - para eliminar as contradições do próprio imperialismo (KAUTSKI, 1914).

Bukharin e Lenin foram os autores que mais combateram a perspectiva kautskiana do ultraimperialismo. Para Bukharin (1988, p. 130), o ultraimperialismo seria irrealizável, pois existem razões de ordem política e social que se oporiam à formação "desse truste universal". Para que tal fosse realizável, seria necessária “[...] uma aproximada igualdade de posições no mercado mundial” (BUKHARIN, 1988, p. 130), para que nenhum participante mais forte que os demais tivesse razões para sair do acordo. Caso existisse uma assimetria, para o participante mais forte "o melhor [...] seria o prosseguimento da luta, sob o bafejo das justas esperanças que acalenta de vencer seu concorrente” (BUKHARIN, 1988,p. 130). A homogeneidade de forças era, portanto, “[...] a regra geral que preside à realização dos acordos. Aplicada aos trustes capitalistas nacionais [...] ela tem o mesmo valor que nos demais casos" (BUKHARIN, 1988,p. 130). Entretanto, no caso específico de acordo entre os capitais nacionais unificados, dever-se-ia levar em consideração duas condições distintas.

Uma primeira condição referiu-se à “igualdade puramente econômica” (BUKHARIN, 1988, p. 130), em se tratando do desenvolvimento das forças produtivas. Um truste capitalista nacional mais desenvolvido em termos econômicos não teria vantagem em se filiar a tal acordo, pois, por ter um aparato técnico mais sofisticado, teria vantagem em termos de custos de produção.

A segunda condição foi definida no nível de "igualdade econômico-política" (BUKHARIN, 1988, p. 131), ou seja, da associação do capital com o Estado. Nessa perspectiva, de acordo com Bukharin (1988, p. 131), “[...] se houver entre os trustes capitalistas nacionais uma sensível 
diferença no tocante às forças militares, o mais forte terá mais interesse em continuar a luta do que em participar de um acordo". Por essas razões, "somos forçados a reconhecer que não se devem esperar, num futuro mais ou menos próximo, [...] uma fusão dos trustes capitalistas nacionais e sua conversão em um único truste mundial” (BUKHARIN, 1988, p. 131).

Bukharin (1988, p. 131) alertou que é necessário estudar essas condições "principalmente sob seu aspecto dinâmico", isto é, do que provavelmente será. Mesmo com essa consideração afirmou que "essa circunstância agrava ainda o estado de desequilíbrio existente" (BUKHARIN, 1988, p. 132).

Em seguida, Bukharin (1988) questionou se, realmente, a corrida armamentista e a crescente militarização prejudicam mais do que beneficiam a burguesia, ao que prosseguiu afirmando que "as vantagens que o grupo nacional da burguesia aufere da continuidade da luta alcançam um valor muito mais alto do que as perdas que dela decorrem" (BUKHARIN, 1988, p. 132). A burguesia “sabe, com perfeição, equilibrar seu ativo e seu passivo" (BUKHARIN, 1988, p. 132), isto é, não vai embrenhar-se em uma insana disputa bélica cujo resultado seria um prejuízo para ela própria. Em tom irônico, afirmou que "a tolice pode ser um traço típico dos pacifistas ingênuos, mas não da burguesia" (BUKHARIN, 1988, p. 132).

Continuando seu argumento, Bukharin (1988, p. 133) raciocinou que "o processo material do desenvolvimento econômico opera-se mediante uma batalha acirrada dos trustes capitalistas nacionais e das demais organizações econômicas. Uma sucessão de guerras torna-se inevitável”. O autor reafirmou que, embora possível teoricamente, o ultraimperialismo é irrealizável. Na realidade, Bukharin (1988) levantou a possibilidade de que acordos bilaterais, como, segundo ele, a unificação de Alemanha e Áustria, ou regionais, como, quiçá, da Europa central, são possíveis e, talvez, realizáveis. Entretanto, qualquer acordo ou consolidação dessa natureza "só fará reproduzir-se em nova escala a sanguinária luta atual” (BUKHARIN, 1988p. 133). À guisa de concluir, o autor apontou a profunda conexão entre o imperialismo e o capitalismo moderno, com o qual se torna impossível esperar um acordo cooperativo entre os trustes capitalistas nacionais:

Desejar pôr fim a essa luta utilizando água benta ou meios improvisados seria a mesma coisa que atirar contra um elefante com grãos de ervilhas. Pois o imperialismo não é só um sistema intimamente ligado ao capitalismo moderno: é seu elemento essencial (BUKHARIN, 1988, p. 133).

A impossibilidade do desarmamento foi refletida por Bukharin (1988) na seguinte passagem:

Os interesses imperialistas são em tal medida essenciais para ao grupos financeiros imperialistas e ligam-se de tal forma às raízes de sua existência, que os governos não se deteriam ante enormes despesas militares tão-somente para garantir para si mesmos uma posição sólida no mercado mundial. No contexto do capitalismo, a ideia do 'desarmamento' torna-se assim particularmente absurda, no que concerne 
aos trustes capitalistas nacionais que ocupam posições avançadas no mercado mundial. (BUKHARIN, 1988, p. 133-134).

De toda forma, caso os países se unam em torno de federação dos países mais fortes, “[...] onde estaria, pois, para um truste capitalista nacional qualquer, a garantia de que, mesmo após compromissos formais e outras garantias, um rival astucioso não recomeçaria a luta 'interrompida'?” (BUKHARIN, 1988, p. 134).

Referindo-se implicitamente a Kautski, Bukharin (1988, p. 135) asseverou: “A crença de que os trustes, essa encarnação dos monopólios, se tornariam os agentes de uma política de expansão pacífica faz parte da fantasia profundamente funesta de um utopista".

Bukharin (1988), concluindo seus argumentos em relação a Kautski, afirmou que a unificação dos trustes capitalistas nacionais no ultraimperialismo representaria o ponto máximo da centralização de capitais. Mas, ao afirmar mais uma vez a impossibilidade real de tal possibilidade teórica, Bukharin (1988) concluiu:

[...] dentro de sua definição capitalista, o processo de centralização choca-se fatalmente com uma tendência sócio-política que lhe é antagônica; não pode, assim, alcançar seu término lógico: aborta e finda sob uma forma não capitalista, nova e depurada. A teoria de Kautsky não é, pois, no mínimo que seja, realista. Não interpreta o imperialismo como o satélite inelutável do capitalismo desenvolvido, mas como um dos 'aspectos sombrios' do desenvolvimento capitalista. [...] Sua concepção leva a dissimular as gigantescas contradições que dilaceram a sociedade moderna e é, por isso, uma concepção reformista. O traço mais característico do reformismo teórico reside em que, escrupulosamente, ele constata todos os elementos de adaptação do capitalismo sem, porém, ver suas contradições. Para um marxista consequente, ao contrário, o desenvolvimento capitalista, em seu conjunto, é apenas um processo de reprodução contínuo e crescente das contradições do capitalismo. (BUKHARIN, 1988, p. 135).

Para Bukharin (1988), o ponto fundamental da crítica reside em que Kautski não considera as contratendências da tendência teórica à centralização máxima dos capitais. O resultado, pois, da crítica de Bukharin (1988, p. 129) é referir-se à hipótese kauskiana como um "quadro idílico", puramente utópico.

Lenin (2008) utilizou, basicamente, a mesma linha de raciocínio de Bukharin (1988). Para ele, embora teoricamente possível, torna-se impossível do ponto de vista da realidade. A história do século XX, segundo Lenin (2008), forneceu alguns exemplos em que a aliança ultraimperialista tornou-se real. Essas alianças aconteceram, por exemplo, nas "relações entre as potências no que se refere à China ${ }^{2} "$ (LENIN, 2008, p. 120).

Embora tenha acontecido e possa, esporadicamente, acontecer novamente, ele se perguntou: "E será concebível [...] pressupondo a manutenção do capitalismo [...], que as referidas alianças não

\footnotetext{
${ }^{2}$ Lenin (2008) está se referindo à partilha do território chinês entre as potências europeias e Japão, no período após a Guerra do Ópio.
} 
sejam efêmeras, que excluam os conflitos e a luta em todas as formas imagináveis?" (LENIN, 2008, p. 120). Logo ele respondeu que não: não serão possíveis "alianças interimperialistas ou ultraimperialistas no mundo real capitalista" (LENIN, 2008, p. 121), pois sob o capitalismo, "é impossível o desenvolvimento igual das diferentes empresas, trusts, ramos industriais e países" (LENIN, 2008, p. 120). Desse modo, a correlação de forças sempre penderá para um lado em detrimento a outro. Para Lenin (2008), a "paz imperialista” (LENIN, 2008, p. 121) precede a “guerra imperialista" (LENIN, 2008, p. 121), e vice-versa.

No prefácio à obra máxima de Bukharin, escrito após o começo da guerra, em 1915, Lenin manifestou que aconteceu o inverso do que Kautski projetara: "o capitalismo pacífico foi substituído por um imperialismo nada pacífico - pelo contrário, belicoso e catastrófico" (LENIN, 1988, p. 12).

Finalizando, Lenin (1988) analisou a diferença entre a possibilidade e a potencial realidade do ultraimperialismo:

Teoricamente, pode-se imaginar uma fase desse tipo. Na prática, porém, ater-se a essa concepção seria cair no oportunismo de pretender ignorar os problemas mais graves da atualidade, para sonhar com problemas menos graves que poderiam vir a impor-se no futuro. No plano teórico, isso significa alienar-se deliberadamente para sonhar, em vez de apoiar-se sobre a evolução, tal qual no momento ela se apresenta. Sem dúvida, a evolução tende para a constituição de um truste único, mundial, abrangendo, sem exceção, todas as empresas e todos os Estados. A evolução efetua-se, porém, em tais circunstâncias e a um ritmo tal, por meio de tais antagonismos, conflitos e convulsões [...] que, antes de chegar-se à criação de um único truste mundial, antes da fusão 'superimperialista' universal dos capitais financeiros nacionais, o imperialismo deverá inevitavelmente estourar e transformar-se em seu contrário (LENIN, 1988, p. 13).

Lenin $(1988$; 2008) e Bukharin (1988) foram os porta-vozes da crítica ao ultraimperialismo kautskiano. Ainda que concordassem que no plano puramente teórico uma configuração desse tipo seria possível, descartaram veementemente essa hipótese, por ser irrealizável do ponto de vista concreto.

Embora seja uma discussão que aborda a configuração capitalista do começo do século XX, é inegável sua contemporaneidade. Autores recentes, utilizando termos, por vezes, diferentes, recaem num debate cuja natureza central é a discussão do ultraimperialismo ${ }^{3}$. Na próxima seção, o modelo teórico explicitado por Bukharin (1988) sobre as condições que tornariam possível a manifestação do ultraimperialismo é reavaliado levando-se em consideração os acontecimentos do capitalismo posteriores ao período das guerras mundiais.

\footnotetext{
${ }^{3}$ Uma síntese de parte desta discussão pode ser encontrada em Leite (2010).
} 


\section{Contribuições do debate clássico para o capitalismo contemporâneo: uma revalidação do modelo teórico}

Nesta seção, o modelo teórico de Bukharin para a possibilidade do ultraimperialismo é recontextualizado. Com isso, foi feito um ajuste nesse modelo para demonstrar outra condição que possibilita a manifestação de um aparente ultraimperialismo.

Analisando ex-post esse debate teórico, pode-se identificar que o capitalismo vivenciou, aparentemente, os dois polos da polêmica: da década de 1910 até 1945, a concepção imperialista de Lenin e Bukharin é a que melhor explica os acontecimentos do período; e de 1945 em diante, o ultraimperialismo de Kautski finalmente se havia materializado. No primeiro período, as duas guerras mundiais e a intensa rivalidade entre as principais potências era uma sinalização clara de que o imperialismo atingira o ápice das contradições. Já no segundo período, essas contradições aparentemente se esvaziam, assim como a possibilidade de guerra intercapitalista. Corrobora essa argumentação a criação dos organismos multilaterais, como, por exemplo, Organização das Nações Unidas (ONU), bem como a maior integração produtiva e financeira entre os capitais nacionais que culmina no período chamado de globalização.

Uma possível explicação para esse movimento pode ser inspirada no modelo teórico proposto por Bukharin (1988). Sua argumentação era que a condição necessária para a realização do ultraimperialismo seria uma relativa igualdade de forças no mercado mundial, que se constitui de dois fatores: i) desenvolvimento das forças produtivas e ii) poderio militar. Caso esta homogeneidade de forças fosse substituída por algum grau de assimetria, para os países líderes não haveria mais vantagens em se filiar a algum acordo de cooperação e, portanto, o ultraimperialismo não seria mais realizável. Bukharin (1988), então, assume apenas dois níveis de homogeneidade: existe ou não existe. Seu modelo teórico pode ser resumido, com elevado grau de simplificação, como segue:

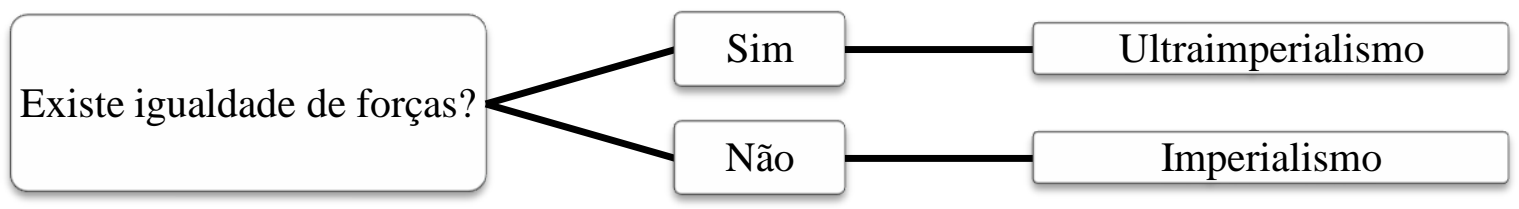

Figura 1: Modelo teórico simplificado de Bukharin para a possibilidade do ultraimperialismo Fonte: Elaboração do autor

No esquema de Bukharin (1988), como dito, a possibilidade do ultraimperialismo é resultado de uma única condição: a relativa igualdade de forças no mercado mundial. Por isso, essa possibilidade foi tomada como irrealizável ou idílica por ele mesmo ou por Lenin (2008). 
Entretanto, esse modelo não se ajusta aos acontecimentos do período pós-II Guerra Mundial. Manifesta-se uma profunda assimetria entre as potências capitalistas, sob liderança dos Estados Unidos e, ao mesmo tempo, um aparente ultraimperialismo. O modelo teórico de Bukharin, portanto, não é capaz de explicar os acontecimentos da fase mais recente do capitalismo. Para isso, necessita-se de que seja incorporado outro elemento: o grau de assimetria entre os países.

Para que o modelo de Bukharin consiga capturar os acontecimentos recentes do capitalismo, um terceiro elemento deverá ser adicionado: caso não haja relativa igualdade de forças, qual o grau de assimetria? Em outras palavras, havendo algum nível de assimetria, qual o tamanho da distância entre o principal líder e os demais? O papel do líder é discutível ou indiscutível?

Foi assumido que o grau de assimetria pode ser decomposto em dois níveis: no nível baixo, a liderança do sistema é discutível, de forma que o mais provável é que o imperialismo em sua forma clássica se manifeste; no nível alto, a liderança é indiscutível, fazendo com que o ultraimperialismo se manifeste - não por causa da relativa igualdade de forças, mas pelo seu mais extremo oposto, onde, por não haver condições de concorrência com o líder, torna-se impossível a manifestação do imperialismo em sua versão clássica. Esse modelo teórico está resumido na figura 2.

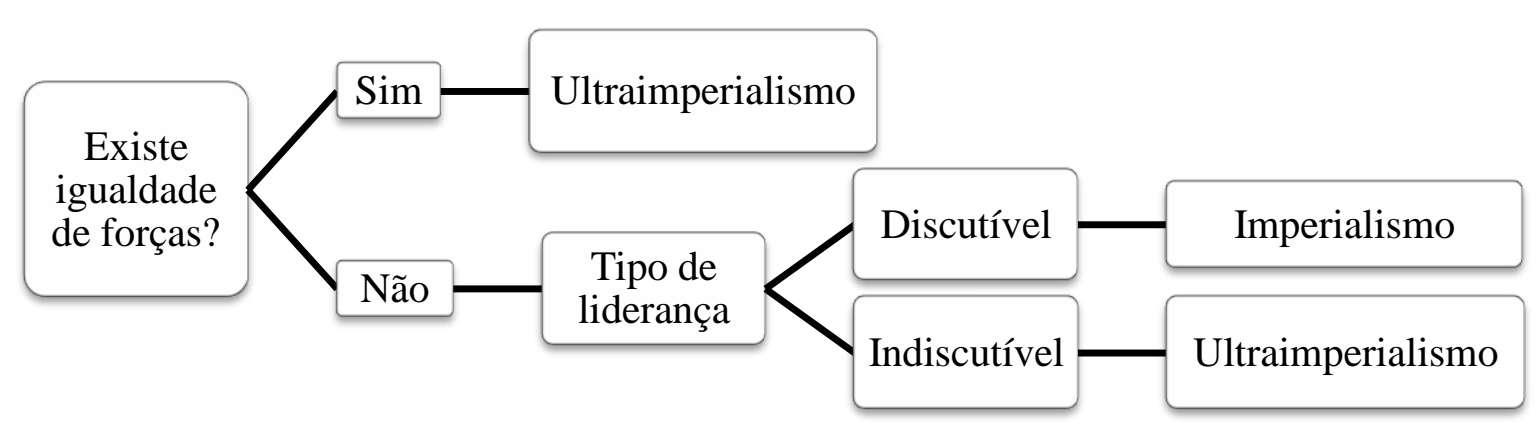

Figura 2: Modelo teórico simplificado de Bukharin incorporado com o grau de assimetria Fonte: Elaboração do autor

Incorporando o grau de assimetria, o que muda em relação ao modelo original é que, caso a liderança seja indiscutível, não existem motivações para a manifestação do imperialismo clássico. $\mathrm{O}$ que ocorre, portanto, é um aparente ultraimperialismo. Decorre que, caso o grau de assimetria diminua, o indiscutível torna-se discutível e a aparência se dissolve: retomam-se as condições concretas para que o imperialismo clássico se manifeste.

\section{Do abstrato ao concreto: uma aplicação empírica para o capitalismo contemporâneo}

Nesta seção são apresentados alguns resultados empíricos que justificam a utilização do modelo teórico desenvolvido na seção anterior.

Assume-se que o aparente ultraimperialismo pós-1945 é decorrente da existência de um líder indiscutível. Essa hipótese foi lançada por Baran e Sweezy (1966), ao discutir a não 
militarização do capitalismo contemporâneo. Para os autores, o sistema capitalista é um sistema internacionalmente hierárquico, com variados graus de superordenação e subordinação. Por uma perspectiva mundial, o capitalismo é considerado "uma rede de relações antagônicas, lançando [países] exploradores contra [países] explorados e exploradores rivais uns contra os outros" (BARAN; SWEEZY, 1966, p. 181). Quanto maior a posição de um país na hierarquia internacional capitalista e quanto maior a intensidade da disputa pelos postos principais nessa cadeia, mais necessidade eles têm das forças armadas.

Nesse sentido, Baran e Sweezy (1966, p. 182) mostram que os séculos XVII e XVIII foram “altamente militarizados", pois foram séculos nos quais não havia ainda uma liderança indiscutível, isto é, vários países disputavam o topo da cadeia internacional e se armavam para essa disputa. Apenas em 1815, com a vitória britânica decisiva e o estabelecimento da Pax Britannica, a ênfase sobre o militarismo declinou. Isso só foi possível graças à ascensão de um líder indiscutível, a Inglaterra, "ocupando o alto e estabilizando todo o sistema por meio de sua própria força e de um sistema flexível de alianças" (BARAN; SWEEZY, 1966, p. 182).

Resgatando a polêmica contemporânea, pode-se dizer que, atualmente, ocorre o mesmo processo. Só existe uma pequena ênfase no militarismo, pois os EUA assumiram o posto de líderes indiscutíveis. Baran e Sweezy (1966, p. 184) afirmam que os Estados Unidos assumiram essa posição logo ao término da Segunda Guerra Mundial. A partir de então, eles passam a assumir "uma posição tão dominante no mundo capitalista quanto o fora a da Grã-Bretanha depois de 1815" Por isso suas despesas militares, mesmo em tempos de paz, permanecem enormes: “o líder indiscutível deve manter uma clara superioridade militar, seja por meio de suas próprias forças armadas, seja pela manipulação de alianças, ou de ambas" (BARAN; SWEEZY, 1966, p 184).

Para testar essa hipótese e verificar como o modelo teórico da seção anterior se ajusta ao capitalismo contemporâneo, foi utilizada a técnica de estatística multivariada denominada análise de clusters (agrupamentos).

\subsection{Base de dados}

Para averiguar o grau de assimetria existente no capitalismo contemporâneo, foram consideradas duas dimensões inspiradas em Bukharin (1988): i) dimensão econômica; e ii) dimensão militar. Na dimensão econômica foram considerado o tamanho da economia dos países, o grau de apropriação de recursos vindos de outros países e o nível de desenvolvimento tecnológico. Para captar essas informações, foram utilizadas as seguintes variáveis, respectivamente: renda 
nacional bruta ${ }^{4}$, renda líquida recebida do resto do mundo e número de patentes registradas por residentes.

Para a dimensão militar, foi considerado o poderio militar. Para captar esta informação, foi utilizada como proxy a variável gastos militares totais. Entende-se que, quanto maiores os gastos militares, maior o poderio militar de cada país ${ }^{5}$.

Para garantir a comparabilidade entre os valores de cada país, os dados foram coletados em uma mesma base de dados, referente ao banco de dados do Banco Mundial (World DataBank World Development Indicators $^{6}$ ). Todas as variáveis, com exceção dos gastos militares totais, foram utilizadas da forma na qual estavam na base referida. Para o cálculo dos gastos militares totais, foram utilizadas duas variáveis: "gastos militares como proporção do PIB" e "PIB a preços constantes". Multiplicando uma pela outra, chegou-se aos gastos militares totais a preços constantes.

Infelizmente, as informações militares estão disponíveis a partir de 1988. Como é um dado imprescindível para a mensuração do grau de assimetria, a análise estatística foi desenvolvida utilizando dados entre 1988 e 2010.

\subsection{Método empírico: análise de clusters}

Para verificar o grau de assimetria, ou o tamanho da distância entre o líder indiscutível e os demais grupos da cadeia imperialista, utilizando as variáveis descritas acima, foi preciso, primeiro, identificar quais grupos são esses. Ao identificar os grupos, foi possível avaliar a evolução da distância entre eles.

A técnica estatística que permite mensurar grupos a partir de múltiplas variáveis é a análise multivariada de clusters. Nesse caso, as observações (os países) foram agrupadas de acordo com o grau de similaridade entre si, de forma que os grupos cumpram duas condições: (i) sejam o mais homogêneos possível; e (ii) que as diferenças entre os grupos sejam as maiores possíveis.

Com base em Johnson e Wichern (1998), o agrupamento é realizado a partir de alguma medida de distância ou dissimilaridade construída a partir das $p$ variáveis envolvidas. Como não foi definido um número de grupos a priori, foi utilizado um método hierárquico de agrupamentos aglomerativo $^{7}$. Esse método inicia-se considerando que cada observação $n$ representa um grupo. Em

\footnotetext{
${ }^{4}$ A escolha pela renda nacional em detrimento à renda interna justifica-se pelo fato de que as atividades dos capitais nacionais em outros países são contabilizadas na primeira e não na segunda métrica.

${ }^{5}$ Ressalte-se que os gastos militares referem-se a uma variável fluxo, enquanto o poderio militar refere-se a uma variável estoque. Mesmo assim, como os gastos militares interferem positivamente no poderio militar, e como existem pouquíssimas informações públicas a este respeito, esta variável se enquadra nos propósitos deste artigo.

${ }^{6}$ Disponível online em <http://databank.worldbank.org/ddp/home.do>.

${ }^{7}$ Em contrapartida, caso o número de grupos já fosse conhecido, seria estabelecido um método não-hierárquico, cuja técnica mais usual é a chamada "k-médias" (JOHNSON; WICHERN, 1998).
} 
seguida, os dois grupos mais próximos de acordo com alguma medida de distância foram fundidos. $\mathrm{Na}$ sequência, os grupos mais similares foram-se fundindo até atingir um único grupo que contivesse todas as observações. Dentro desse intervalo, de $n$ até um grupo, foi feito um recorte e estabelecido o número ideal de grupos.

Operacionalmente, foi preciso definir qual medida de distância e qual método de ligação entre os grupos foram utilizados. Como existem várias métricas de distância e vários algoritmos de ligação, foi escolhido um par - o mais usual.

Em relação à medida de distância, foi utilizada a métrica euclidiana. A distância euclidiana (d) entre duas observações $p$-dimensionais (cada dimensão representa uma variável) $\mathbf{x}$ e $\mathbf{y}$, em escala matricial ${ }^{8}$, é definida como:

$$
d(\mathbf{x}, \mathbf{y})=\sqrt{(\mathbf{x}-\mathbf{y})^{\prime}(\mathbf{x}-\mathbf{y})}
$$

Onde $\mathbf{x}=\left[x_{1}, x_{2}, \ldots, x_{p}\right]^{\prime}$ e $\mathbf{y}=\left[y_{1}, y_{2}, \ldots, y_{p}\right]^{\prime}$ representam duas observações quaisquer.

Em relação à medida de ligação, foi utilizado o método de Ward. Esse algoritmo é baseado na minimização da perda de informação derivada da união entre dois grupos. Considerando que a soma dos quadrados dos erros (SQE) seja a soma dos desvios ao quadrado de cada item (observação) dentro do grupo em relação à média (centroide) do próprio grupo, segue que $S Q E_{k}$ representa a soma dos quadrados dos erros do cluster $k$.

Considerando que $S Q E^{*}=\sum S Q E_{k}$, a união entre dois grupos $k$ e $i, k \neq i$, foi realizada somente quando a combinação entre eles resultar no menor aumento na $S Q E^{*}$ dentre todas as combinações possíveis. Dadas essas condições, foram realizadas combinações sucessivas entre dois grupos até se formar um único grupo contendo todas as observações. Os resultados desse método podem ser visualizados em um dendrograma, onde o eixo vertical fornece os valores da distância em que cada união entre dois grupos ocorreu. No eixo horizontal foram representadas as observações por grau de similaridade entre si.

\section{Resultados}

A análise de agrupamentos foi realizada ano a ano, de 1988 a 2010. Para cada ano obteve-se um dendrograma, no qual são apresentados os elos que ligam os países. No eixo vertical encontra-se a distância com a qual os grupos de países foram se formando - neste caso, foi utilizada a distância euclidiana, por ser a mais usual em pesquisas que utilizam essa metodologia. Quanto mais baixa está a linha horizontal que liga grupos distintos, maiores as similaridades entre esses grupos.

\footnotetext{
${ }^{8}$ Variáveis indicadas com negrito e minúsculo representam vetores.
} 
Foram apresentados os nodos superiores dos dendrogramas (sempre com os vinte países que ocupam as maiores posições) para anos selecionados (1990, 2000 e $2010^{9}$ ), que delimitam de forma bastante clara o que se pretende demonstrar aqui. No período analisado, um padrão se mantém em todos os anos: os Estados Unidos formam, por si só, um único agrupamento. Significa que os EUA apresentam, de acordo com as variáveis utilizadas no estudo, características completamente diferentes de todos os outros países; indicando uma robusta evidência a favor da hipótese do líder indiscutível.

Do ponto de vista da distância dos EUA, em relação aos outros agrupamentos, constata-se uma mudança de trajetória ao longo do período. Em 1990, essa distância estava acima de 7x10 13 (Figura 3). Ao longo dos anos 1990, ela vai diminuindo até se estabilizar em torno de 6x10 ${ }^{13}$ no ano 2000 (Figura 4). Após 2001, essa distância começa a crescer rapidamente, atingindo 12x10 13 (igual a $1,2 \times 10^{14}$ ) em 2010 (Figura 5). Cabe ressaltar que o que é relevante, para os propósitos desta pesquisa, não é a magnitude da distância em si, mas sim sua dinâmica, isto é, a análise de sua trajetória ao longo do tempo. Como o período de análise é relativamente pequeno, não é possível identificar se esta inflexão na distância dos EUA corresponde a um movimento conjuntural ou estrutural. De todo modo, é possível verificar que os anos 1990 corresponderam a um período de diminuição relativa da distância do líder indiscutível, fato invertido a partir dos anos 2000; cuja explicação repousa no acréscimo substancial nos gastos militares após os ataques terroristas de $11 / 09 / 2001$.

Outra mudança qualitativa que se torna clara com a inspeção dos dendrogramas é a entrada da China no segundo agrupamento mais poderoso. Em 1990, por exemplo, a China estava mais próxima de países como Coréia do Sul, Canadá e Índia do que países como Japão, Reino Unido e Estados Unidos. Inclusive o Brasil encontrava-se em agrupamento mais poderoso do que a China, como pode ser analisado na Figura 3.

\footnotetext{
${ }^{9}$ A pesquisa gerou dendrogramas para todos os anos analisados, que não estão apresentados aqui por questão de espaço. O leitor interessado nestes gráficos pode entrar em contato com o autor via correio eletrônico.
} 


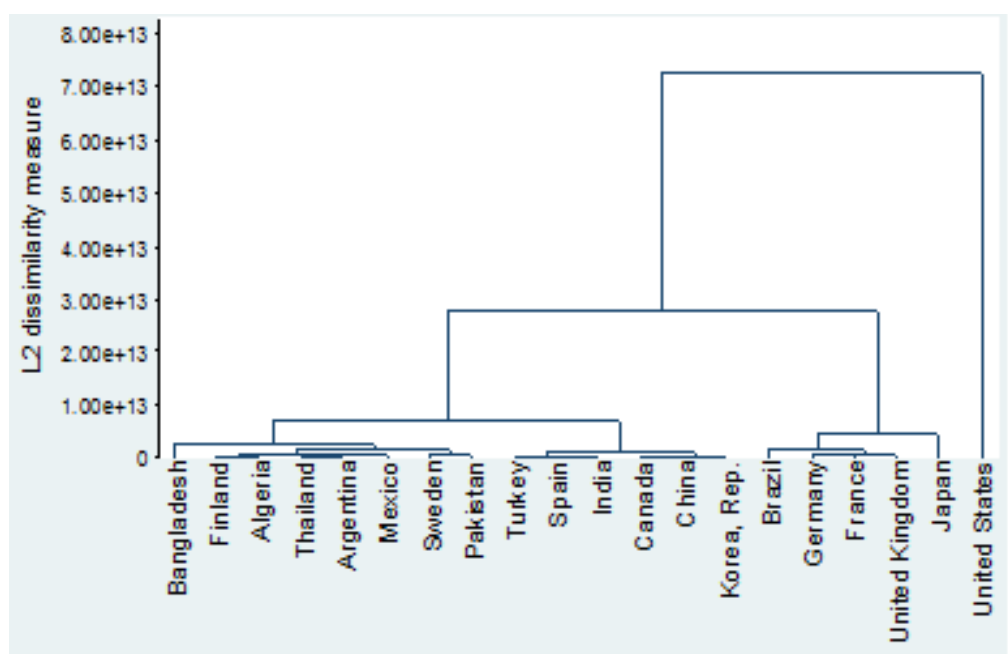

Figura 3: Agrupamentos, ano 1990

Fonte: Elaboração do autor

Os anos 1990 marcam o ingresso da China ao redor das potências capitalistas. Em 2000, utilizando a distância de $1 \times 10^{13}$ como a linha de corte entre os grupos, a China aparece no segundo agrupamento mais poderoso ao lado de Japão, Reino Unido e Alemanha. O Brasil, nesta comparação relativa, perde posições e se agrupa com países como Arábia Saudita, Índia, Israel, Austrália e Canadá (Figura 4).

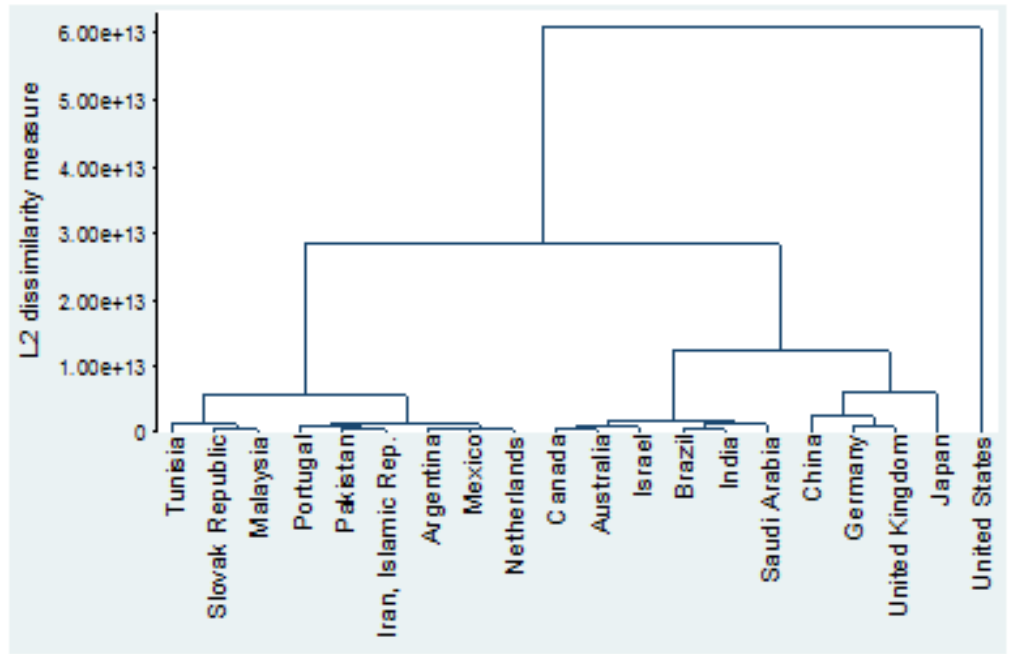

Figura 4: Agrupamentos, ano 2000

Fonte: Elaboração do autor

Nos anos 2000, a China se consolida no segundo agrupamento e, dentro dele, como a principal potência. Além do ponto de vista econômico, no plano militar a China está executando grandes investimentos que a fazem surgir como potencial player na esfera internacional - como mostra a mídia especializada e relatório do próprio Departamento de Defesa do Governo dos Estados Unidos ${ }^{10}$. Utilizando a distância de corte de $2 \times 10^{13}$, Japão, Reino Unido, França e

\footnotetext{
${ }^{10}$ A mídia especializada corresponde a The Economist (2010, 2011). O relatório do Pentágono pode ser encontrado em US Department of Defense (2011).
} 
Alemanha compõem, com a China, o segundo agrupamento em 2010. O terceiro, do qual o Brasil faz parte, apresenta uma similaridade maior com o quarto do que com o segundo grupo em 2010 ao contrário de 2000, quando estava mais próximo do segundo que do quarto.

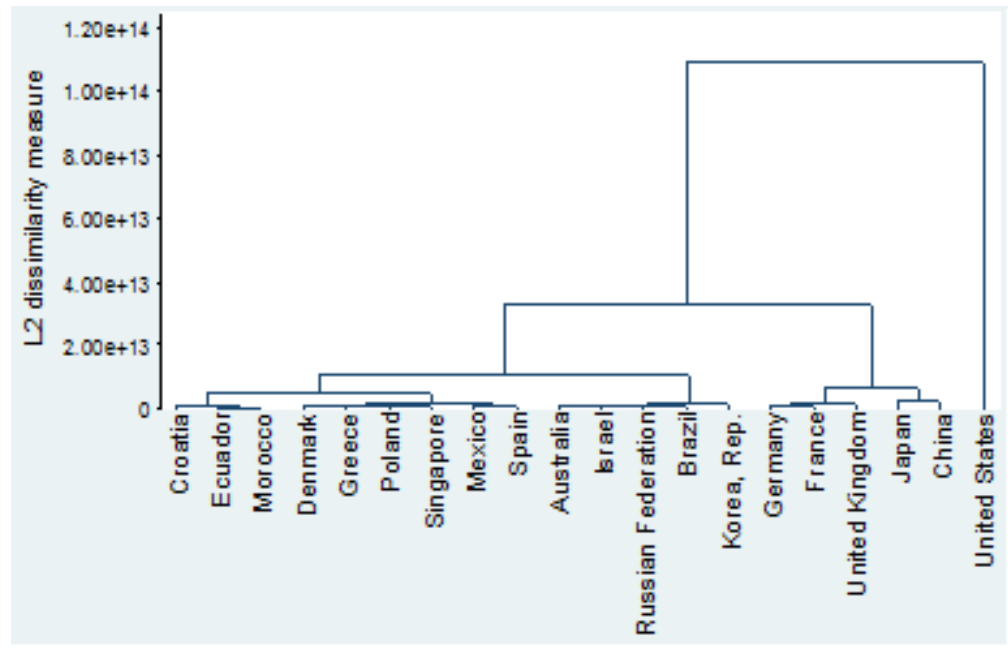

Figura 5: Agrupamentos, ano 2010

Fonte: Elaboração do autor

Em síntese, a década de 2000 indica que o esforço militar dos Estados Unidos resgatou seu papel de líder indiscutível; posição que estava em declínio na década de 1990. Por outro lado, consolidou a China como segundo posto da economia mundial capitalista.

\section{Considerações Finais}

Esta pesquisa foi motivada por uma disputa teórica e uma constatação empírica. A primeira foi marcada pelo destacado embate entre Lênin e Kautski, principalmente no que se refere aos prognósticos do capitalismo. A posição de Lênin pode ser resumida em uma de suas famosas frases, segundo a qual a paz imperialista precede a guerra imperialista. Kautski, por outro lado, garantia que a paz duradoura - o ultraimperialismo - poderia consolidar-se como a regra de ouro do capitalismo inaugurando uma nova era de esperança.

O século XX demonstrou - e nisso reside a constatação empírica - que os dois polos da polêmica podem ter sua razão. Enquanto a primeira metade poderia ser a prova cabal de que o imperialismo conduziria a guerras fratricidas, cujos horizontes para o capitalismo poderiam ser tenebrosos; a segunda metade demonstrou exatamente o contrário, isto é, que o imperialismo não caminha necessariamente para sua própria aniquilação, que pode existir uma convivência pacífica entre as grandes potências mesmo no quadro da mais alta concentração do capital.

Como conciliar então esses acontecimentos do século $\mathrm{XX}$ com o modelo teórico que demonstra a impossibilidade concreta de realização do ultraimperialismo? Esta foi a questão que norteou essa pesquisa. Espera-se ter demonstrado que o conceito de imperialismo como estágio 
final da acumulação capitalista continua válido. $O$ que se manifestou (pós-1945) como ultraimperialismo pode ser incorporado à noção do imperialismo, ao se considerar a possibilidade de existência de um líder indiscutível. Incorporando esse conceito ao modelo teórico explicitado por Bukharin, pode ser concluído que o aparente ultraimperialismo pode ser convertido novamente em imperialismo - basta, para isso, que o líder indiscutível se torne discutível. Portanto, o que se manifestou (e se manifesta) como ultraimperialismo não é nada mais do que uma fase particular dentro do estágio final do imperialismo.

Pretende-se, então, ter contribuído com o entendimento do capitalismo no século XXI. Considerando o ultraimperialismo como uma fase particular dentro do imperialismo e que transições entre as fases ou estágios do capitalismo ocorrem como reflexos das crises estruturais, conclui-se que existe uma alta probabilidade de que a crise atual esteja marcando historicamente a transição entre fases distintas dentro do imperialismo e do capitalismo. Caso esta constatação esteja correta, ainda é cedo para identificar os principais traços desta nova fase do imperialismo. Para isso, entende-se que a pesquisa empírica e quantitativa pode ajudar nessa caracterização.

Nesse sentido, utilizou-se um método estatístico como uma tentativa de iluminar algumas questões ainda em aberto. Por exemplo, demonstrou-se que do ponto de vista econômico e militar, os Estados Unidos podem ser rotulados como o líder indiscutível da fase corrente do capitalismo. Ademais, sua distância para o segundo grupo decresceu na década de 1990 e, por outro lado, se fortaleceu na década de 2000. Está em aberto - e merece estudos mais aprofundados - se o declínio na década de 1990 foi a continuidade de um processo estrutural de mais longo prazo ou se foi resultado de movimentos conjunturais. Ao mesmo tempo, também está inconcluso se, na década de 2000, os fatores que levaram à inversão do processo de declínio podem ser mantidos para o futuro.

Por fim, outra possibilidade de pesquisa futura é em relação à posição do Brasil na cadeia interimperialista global. Pelo método utilizado neste artigo, o Brasil situa-se entre o segundo e o terceiro agrupamento. As consequências disso, implicações para a dinâmica de classes interna e se é a manifestação de um subimperialismo ou não, merecem estudos mais aprofundados.

\section{Referências}

BARAN, Paul. A.; SWEEZY, Paul M. Capitalismo Monopolista: ensaio sobre a ordem econômica e social americana. Tradução de Waltensir Dutra. Rio de Janeiro: Zahar, 1966. 383p.

BREWER, Anthony. Marxist Theories of Imperialism: a critical survey. 2.ed. London:

Routledge, 1990. 300p. crossref http://dx.doi.org/10.4324/9780203003817

BUKHARIN, Nicolai. A economia mundial e o imperialismo. Tradução de Raul de Carvalho. São Paulo: Nova Cultural, 1988. 164p.

CIPOLLA, Francisco P. Interpretações marxistas da crise atual. In: XV encontro Nacional de

Economia Política, São Luís, 2010. 
FONTES, Virgínia. Lenin, o imperialismo e os desafios contemporâneos. In: Revista Margem Esquerda: ensaios marxistas, n.10. São Paulo: Boitempo, 2007. p.54-61.

HILFERDING, Rudolf. O Capital Financeiro. Tradução de Reinaldo Mestrinel. São Paulo: Nova Cultural, 1985. 346p.

JOHNSON, R.; WICHERN, D. Applied Multivariate Statistical Analysis. 4. ed. New Jersey: Prentice Hall, 1998. 816 p.

KAUTSKI, Karl. Ultra-imperialism. 2014. Disponível em:

<http://www.marxists.org/archive/kautsky/1914/09/ultra-imp.htm>. Acesso em: 08 nov. 2009.

O Imperialismo. In: TEIXEIRA, Aloisio (org.). Utópicos, Heréticos e Malditos: os precursores do pensamento social de nossa época. Rio de Janeiro: Record, 2002a. p. 443-463

Dois artigos para revisão. In: TEIXEIRA, Aloisio (org.). Utópicos, Heréticos e Malditos: os precursores do pensamento social de nossa época. Rio de Janeiro: Record, 2002b. p. 465-490.

LENIN, Vladimir Ilitch. O Imperialismo: fase superior do capitalismo. 4.ed. Tradução de Leila Prado. São Paulo: Centauro, 2008. 130p.

Prefácio. In: BUKHARIN, Nicolai. A Economia Mundial e o Imperialismo. São Paulo: Nova Cultural, 1988. p. 9-13.

LEITE, Leonardo M. Existe uma teoria do imperialismo contemporâneo? In: XV encontro Nacional de Economia Política, São Luís, 2010.

LUXEMBURG, Rosa. A acumulação do capital: estudo sobre a interpretação econômica do imperialismo. 2.ed. Tradução de Moniz Bandeira. Rio de Janeiro: Zahar, 1976. 516p.

ROXBURGH, C. et al. Debt and deleveraging: the global credit bubble and its economic consequences. McKinsey Global Institute, 2010.

SAKELLAROPOULOS, Spyros. The Issue of Globalization through the Theory of Imperialism and the Periodization of Modes of Production. Critical Sociology, Thousand Oaks, v.35, n.1, p.57-78, 2009. crossref $\mathrm{http}: / / \mathrm{dx}$.doi.org/10.1177/0896920508098657

THE ECONOMIST . China is becoming a military force to reckon with in the western Pacific. How should America respond? In: The Economist online. 2010. Disponível em:

<http://www.economist.com/node/17601487>. Acesso em: 02/08/2011.

THE ECONOMIST Modernisation in sheep's clothing. The Economist online, 2011. Disponível em: <http://www.economist.com/blogs/banyan/2011/08/chinas-military-power >. Acesso em: 27/08/2011.

US DEPARTMENT OF DEFENSE, Military and Security Developments Involving the People's Republic of China: 2011. Annual Report to Congress.2011. Disponível em: <http://www.defense.gov/pubs/pdfs/2011_CMPR_Final.pdf>. Acesso em: 27/08/2011.

Recebido em 20.09.13

Aprovado em 03.07.14 